\title{
Bazı Şeker Pancarı Çeşitlerinin Eskişehir Koşullarındaki Performansları
}

\author{
*Engin Gökhan KULAN ${ }^{*}$ Mehmet Demir KAYA ${ }^{1}$ Ertuğrul KARAŞ² \\ ${ }^{1}$ Eskişehir Osmangazi Üniv., Ziraat Fakültesi, Tarla Bitkileri Bölümü, Eskişehir \\ ${ }^{2}$ Eskişehir Osmangazi Üniv., Ziraat Fakültesi, Biyosistem Müh. Bölümü, Eskişehir \\ *Sorumlu yazar e-posta (Corresponding author e-mail): egk_88@hotmail.com
}

Öz

Bu çalışma Eskişehir koşullarında bazı şeker pancarı çeşitlerinin verim ve polar şeker oranı bakımından performanslarının değerlendirilmesi amacıyla 2014 yılında yürütülmüştür. Araştırmada Valentina, Agnessa, Calixta, Zanzibar, Bison, Mohican, Maden, Esperanza ve Pauletta olmak üzere dokuz şeker pancarı çeşidi kullanılmıştır. Tesadüf blokları deneme desenine göre kurulan araştırma 4 tekrarlamalı olarak yürütülmüştür. Araştırmada tarla çıkış (\%), kök-gövde boyu (cm), kök-gövde çapı (cm), kök-gövde ağırlığı (g/bitki), kökgövde verimi ( $\mathrm{kg} / \mathrm{da}$ ) ve polar şeker oranı (\%) özellikleri incelenmiştir. Araştırma sonuçları, incelenen özellikler bakımından çeşitler arasında önemli farklılıklar belirlenmiştir. Çeşitler arasında en yüksek kök ağırığı 1330 g/bitki ile Mohican, kök verimi 10254 kg/da ile Esperanza, polar şeker oranı \%15.63 ile Zanzibar, kök boyu $24.47 \mathrm{~cm}$ ile Maden, kök çapı $12.37 \mathrm{~cm}$ ile Esperanza ve tarla çıkışı \%92.16 ile Bison çeşitlerinden elde edilmiştir. İncelenen karakterler bakımından çeşitlerin farklı özelliklere sahip olduğu söylenebilir. Sonuç olarak, incelenen çeşitler arasında Maden, Agnessa ve Zanzibar çeşitlerinin yüksek verime, Calixta, Zanzibar ve Maden çeşitlerinin ise yüksek polar şeker oranına sahip oldukları belirlenmiştir.

Anahtar Kelimeler: Beta vulgaris L., verim, çeşit, polar şeker oranı

\section{Performance of Some Sugar Beet Cultivars in Eskişehir Conditions}

\begin{abstract}
This was conducted to determine the performance of some sugar beet cultivars in Eskişehir conditions in 2014. Nine sugar beet cultivars Valentina, Agnessa, Calixta, Zanzibar, Bison, Mohican, Maden, Esperanza and Pauletta were used in the study. The experiment was established as randomized complete block design with four replications. Field emergence $(\%)$, root length $(\mathrm{cm})$, root diameter $(\mathrm{cm})$, root weight $(\mathrm{g} / \mathrm{plant})$, root yield $(\mathrm{kg} / \mathrm{da})$ and polar sugar content $(\%)$ were investigated. The results of the experiment showed that a significant difference among the sugar beet cultivars was found. Mohican gave the highest root weight with $1330 \mathrm{~g} /$ plant while root yield was obtained in Esperanza with $10254 \mathrm{~kg} / \mathrm{da}$. Among the cultivars Bison possessed the better field emergence performance than the others. It was concluded that Maden, Agnessa and Zanzibar should be preferred for high root yield, and Calixta, Zanzibar and Maden for polar sugar content.
\end{abstract}

Keywords: Beta vulgaris L., yield, cultivar, polar sugar content

\section{Giriş}

ü Ikemizde şeker pancarı ıslah çalışmaları ve tohumluk üretimi tamamen özel sektör tohumluk firmaları tarafından gerçekleştirilmektedir. 2015 yılı verilerine göre 95 adet tescilli, 6 adet üretim izinli olmak üzere 101 adet şeker pancarı çeşidi kayıt altındadır (Anonim 2015a). Çeşit sayısının fazla olması ve hemen hemen her yıl yeni pancar çeşitlerinin tescil edilmesi nedeniyle bu çeşitlerin farklı bölgelerdeki performanslarının test edilmesi gerekmektedir. Eskişehir şeker pancarı ekim alanı bakımından
166.649 da ile ülkemizde Konya ve Yozgat ilinden sonra üçüncü sırada yer almaktadır (Anonim 2015b). Eskişehir'de şeker pancarı üretimi $941.487 \mathrm{ton}$, verimi ise $5650 \mathrm{~kg} / \mathrm{da}$ olarak gerçekleşmiştir. Bu değerlerle ülkemiz ekim alanlarının ve üretiminin yaklaşık \%6'sını karşılamaktadır. Verim bakımından ise Türkiye ortalaması olan $5765 \mathrm{~kg} / \mathrm{da}$ 'ın altında bir verim gerçekleşmektedir. Eskişehir şeker pancarı ekim alanı bakımından 3. sırada yer almasına rağmen, verimin ülke ortalamasının altında kalması 
nedeniyle üretilen pancar miktarını azaltmaktadır. $\mathrm{Bu}$ nedenle başta şeker pancarı verimini arttıracak tarımsal uygulamalar olmak üzere, bölge şartlarına adaptasyonu yüksek olan çeşitlerin seçimine de önem verilmesi gerekmektedir. Bu çalışma bazı şeker pancarı çeşitlerinin Eskişehir koşullarındaki verim potansiyellerinin belirlenmesi amacıyla yürütülmüştür.

\section{Materyal ve Yöntem}

$\mathrm{Bu}$ araştırma 2014 yılında Eskişehir Osmangazi Üniversitesi Ziraat Fakültesi Tarla Bitkileri Bölümü'nde yürütülmüştür. Çalışmada Valentina, Agnessa, Calixta, Mohican, Maden, Esperanza, Pauletta, Zanzibar ve Bison şeker pancarı çeşitlerine tohumlar kullanılmıştır.

Deneme alanının farklı yerlerinden alınan toprak örneklerinde toprak yapısı ve toprağın bazı kimyasal özellikleri bakımından yapılan analiz sonuçlarına göre, deneme alanı toprağı killi-tınlı yapıya sahip olup, hafif alkali, orta derecede kireçli, tuzsuz, fosfor ve organik maddece düşük, potasyumca yeterli olduğu belirlenmiştir. Deneme alanının drenajı iyi ve taban suyu problemi bulunmamaktadır.

Araştırmanın yürütüldüğü 2014 yılına ait aylık ortalama sıcaklık $\left({ }^{\circ} \mathrm{C}\right)$, nispi nem (\%) ve toplam yağış $(\mathrm{mm})$ değerleri ile bunların uzun yıllar ortalaması Çizelge 1' de gösterilmiştir. Yağış bakımından uzun yıllar ortalamasına yakın değerler görülmesine rağmen vejetasyon döneminde toplam $273.1 \mathrm{~mm}$ yağış alınmıştır. Bu değer vejetasyon döneminin uzun yıllar ortalaması olan 137.0 mm'nin oldukça üzerinde gerçekleşmiştir. Yağışın fazla olduğu aylarda ortalama sıcaklığın daha düşük gerçekleşmesine neden olmuştur.

Deneme tesadüf blokları deneme desenine göre 4 tekerrürlü olarak kurulmuştur. Ekim

Çizelge 1. Deneme alanına ait bazı iklim verileri Table 1. Some meteorological data of experimental site

\begin{tabular}{ccccccc}
\hline \multirow{2}{*}{ Aylar } & \multicolumn{3}{c}{ Uzun yıllar $(1970-2013)$} & \multicolumn{2}{c}{2014} & Sem $(\%)$ \\
\cline { 2 - 6 } & Yağış $(\mathrm{mm})$ & Sıcaklık $\left({ }^{\circ} \mathrm{C}\right)$ & Nem $(\%)$ & Yağış $(\mathrm{mm})$ & Sıcaklık $\left({ }^{\circ} \mathrm{C}\right)$ & N \\
Ocak & 30.6 & -0.2 & 75.2 & 13.6 & 3.0 & 84.1 \\
Şubat & 26.1 & 0.9 & 70.6 & 5.8 & 4.2 & 68.2 \\
Mart & 27.6 & 4.9 & 64.2 & 23.1 & 6.3 & 68.4 \\
Nisan & 43.1 & 9.6 & 62.7 & 15.2 & 11.5 & 62.7 \\
Mayıs & 40.0 & 14.9 & 59.5 & 27.2 & 15.1 & 66.2 \\
Haziran & 23.7 & 19.1 & 55.2 & 70.6 & 18.5 & 66.9 \\
Temmuz & 13.1 & 22.1 & 51.9 & 7.5 & 22.6 & 58.6 \\
Ağustos & 9.2 & 21.8 & 53.6 & 27.0 & 23.0 & 59.8 \\
Eylül & 18.1 & 16.7 & 58.4 & 82.7 & 17.4 & 70.7 \\
Ekim & 32.8 & 11.7 & 64.7 & 42.9 & 12.2 & 78.9 \\
Kasım & 34.0 & 5.6 & 70.5 & 15.6 & 6.3 & 80.9 \\
Aralık & 40.5 & 1.7 & 75.9 & 26.8 & 5.0 & 87.8 \\
\hline Toplam & 338.8 & & - & 358.0 & - & - \\
Ortalama & - & 10.7 & 71.1 & - & 12.1 & 62.3 \\
\hline
\end{tabular}

Çizelge 2. İncelenen şeker pancarı çeşitlerinin verim ve verim öğelerine ait ortalama ve farklılık grupları Table 2. Averages and difference groups of yield and some yield components of sugarbeet cultivars

\begin{tabular}{|c|c|c|c|c|c|c|}
\hline Çeşit & $\begin{array}{c}\text { Kök ağırlığı } \\
\text { (g/bitki) }\end{array}$ & $\begin{array}{c}\text { Kök verimi } \\
(\mathrm{kg} / \mathrm{da})\end{array}$ & $\begin{array}{c}\text { Polar şeker } \\
\text { oranı (\%) }\end{array}$ & $\begin{array}{l}\text { Kök boyu } \\
(\mathrm{cm})\end{array}$ & $\begin{array}{c}\text { Kök çapı } \\
(\mathrm{cm})\end{array}$ & Çıkış (\%) \\
\hline Valentina & $925^{\mathrm{C}}$ & $9156^{\mathrm{abc} 123}$ & $14.21^{b}$ & $19.97^{\mathrm{d} 3^{*}}$ & 11.17 & 91.2 \\
\hline Agnessa & $1315^{a}$ & $9554^{\mathrm{ab} 123}$ & $15.15^{a}$ & $23.00^{\mathrm{ab} 12}$ & 12.10 & 88.2 \\
\hline Calixta & $1124^{\mathrm{abc}}$ & $7792^{\mathrm{cd} 3}$ & $15.48^{\mathrm{a}}$ & $21.07^{\mathrm{cd} 23}$ & 12.27 & 89.2 \\
\hline Mohican & $1330^{\mathrm{a}}$ & $9380^{\mathrm{ab} 123}$ & $14.97^{a}$ & $22.87^{\mathrm{abc} 12}$ & 12.13 & 82.4 \\
\hline Maden & $1196^{a b}$ & $9868^{\mathrm{a} 12}$ & $15.34^{a}$ & $24.47^{\mathrm{a} 1}$ & 12.10 & 81.4 \\
\hline Esperanza & $1232^{\mathrm{ab}}$ & $10250^{\mathrm{a} 1}$ & $15.12^{\mathrm{a}}$ & $21.73^{\mathrm{bcd} 23}$ & 12.37 & 88.2 \\
\hline Pauletta & $1059^{b c}$ & $7772^{\mathrm{d} 3}$ & $15.13^{a}$ & $23.40^{\mathrm{ab} 12}$ & 10.93 & 81.4 \\
\hline Zanzibar & $1255^{a b}$ & $9763^{\mathrm{a} 12}$ & $15.63^{a}$ & $22.67^{\mathrm{abc} 12}$ & 12.20 & 85.0 \\
\hline Bison & $1095^{\mathrm{bc}}$ & $8244^{\mathrm{bcd} 23}$ & $14.98^{\mathrm{a}}$ & $22.33^{\mathrm{bc} 123}$ & 11.17 & 92.2 \\
\hline
\end{tabular}

*: Harfler \%5, rakamlar \%1 düzeyinde farklı grupları göstermektedir.

* Letters and numbers stands for $\% 5$ and $\% 1$ difference groups, respectively 
$45 \times 25 \mathrm{~cm}$ bitki sıklığı ile 11.04.2014 tarihinde $4.0 \times 1.8 \mathrm{~m}=7.2 \mathrm{~m}^{2}$ lik parsellere 4 sıra olarak yapılmıştır. Ekimden önce dekara $25 \mathrm{~kg}$ Diamonyum fosfat (DAP 18-46-0) gübresi uygulanmıştır. Çıkış tamamlandıktan sonra bir kez el çapası yapılmıştır. Üst gübreleme olarak $20 \mathrm{~kg} / \mathrm{da}$ amonyum sülfat (\%21 N) gübresi ikinci sulamadan önce verilmiştir. Sulama 15 haziran15 eylül tarihleri arasında yağmurlama sulama yöntemiyle gerçekleştirilmiştir. Yağmurlama başlıkları $15 \times 10 \mathrm{~m}$ tertip düzeninde yerleştirilmiş ve saatte 2 ton su veren yağmurlama başlıkları kullanılmıştır. Etkili kök derinliği $90 \mathrm{~cm}$ olacak şekilde alınmıştır. Sulama aralığı 18 gün, sulama sayısı 6 olacak şekilde sulama uygulanmıştır. Tüm yetiştirme periyodu boyunca $500 \mathrm{~mm}$ sulama suyu uygulanmıştır. Hasat 18.10.2014 tarihinde yapılmıştır. Parsellerde sökülen bitkilerde ölçümler tamamlandıktan sonra polar şeker oranlarının belirlenmesi Eskişehir Şeker Fabrikası'nda polarimetre yardımıyla belirlenmiştir.

Elde edilen verilerin tesadüf blokları deneme desenine göre varyans analizi yapılmıştır. Uygulamalar arasındaki farkların önem düzeylerini belirleyebilmek amacıyla Duncan Çoklu Karşılaştırma Testi uygulanmıştır (Düzgüneş ve ark. 1987). Tüm istatistiksel hesaplamalar bilgisayarda MSTAT-C (Michigan State University, version 2.10) paket programı kullanılarak yapılmıştır.

\section{Bulgular ve Tartışma}

İncelenen şeker pancarı çeşitlerine ait kökgövde ağırlığı, kök-gövde verimi, polar şeker oranı, kök-gövde boyu, kök-gövde çapı ve çıkış oranına ait elde edilen ortalamalar ve farklılık gruplandırmaları Çizelge 2'de gösterilmiştir. Kök-gövde çapı ve çıkış oranı hariç incelenen tüm özelliklerde çeşitler arasında belirlenen farklılıklar istatistiksel olarak önemli bulunmuştur. Kök-gövde ağırlığı bakımından şeker pancarı çeşitleri arasında belirlenen farklılıklar istatistiksel olarak $\% 5$ seviyesinde önemli bulunmuştur. En yüksek kök ağırlığı 1330 g/bitki ile Mohican çeşidinden elde edilmiş, bunu sırasıyla Agnessa (1315 g/bitki) ve Zanzibar (1255 g/bitki) çeşitleri izlemiştir. Çeşitlerin kök-gövde ağırlıkları arasında farklılıkların bulunduğu Tunçtürk (2005) tarafından da bildirilmiştir. Dekara kök-gövde verimi ise en yüksek Esperanza çeşidinden 10250 kg/da ile elde edilmiştir. Çeşitler arasında en düşük dekara kök-gövde verimi 7772 kg/da ile Pauletta çeşidinde belirlenmiştir. Bulgularımız çeşitlerin kök-gövde verimleri arasında farklılıkların bulunduğu bildiren Söğüt ve Arıoğlu (1999), Günel ve İlbaş (1994) ve Tunçtürk (2005)'ün sonuçlarını destekler niteliktedir. Ayrıca Ada ve ark. (2012) sekiz şeker pancarı çeşidinde kök-gövde veriminin 4080-7340 kg/da arasında değiştiğini ve çeşitler arasında $3000 \mathrm{~kg} / \mathrm{da}$ 'dan fazla verim farklılığı olduğunu belirlemiştir.

Çalışmamızda benzer sonuçlar elde edilmiştir. Çeşitlerinin polar şeker oranı arasında istatistiksel olarak önemli farklılıklar belirlenmesine rağmen, Valentina çeşidi hariç diğer çeşitlerin istatistiksel olarak aynı grupta yer aldığı görülmektedir. Valentina çeşidi ise \%14.21 ile en düşük polar şeker oranına sahip olmuştur. Sonuçlarımız, çeşitlerin şeker oranları bakımından farklı olduğu, polar şeker oranının iklim ve toprak faktörlerinden etkilendiğini ve lokasyonlara göre önemli farklılıklar gösterdiğini tespit eden Karadoğan ve Kurtçebe (2005) tarafından desteklenmektedir. Kök-gövde boyu bakımından çeşitler farklı bulunmuş, en uzun kök boyu $24.47 \mathrm{~cm}$ ile Maden çeşidinde, en kısa ise $19.97 \mathrm{~cm}$ ile Valentina çeşidinde belirlenmiştir. Okut ve Yıldırım (2004) çeşitlerin kök boyları arasında farklılıklar belirlerken, Ada ve ark. (2012) belirlememiştir. Bu duruma genetik faktörlerin yanında özellikle farklı toprak şartlarının etkili olabileceği düşünülmektedir. Kök-gövde çapı bakımından incelenen şeker pancarı çeşitleri arasında önemli bir farklılık belirlenmemiş ve 10.93-12.37 cm arasında değişim göstermiştir. Benzer şekilde çeşitlerin kök-gövde çapı arasında önemli farklılıklar bulunmadığı Ada ve ark. (2012) tarafından bildirilmiştir. Çeşitlerin çıkış oranın da önemli bir farklılık belirlenmemiş ve \%81.4 - 92.2 değişmiştir. Bununla birlikte Bison (\%92.2) ve Valentina (\%91.2) çeşitlerinden daha yüksek çıkış oranı elde edilmiştir.

\section{Sonuç}

Sonuç olarak incelenen şeker pancarı çeşitlerinin verim bakımından gösterdikleri farklılıklar oldukça yüksek bulunmuş, en yüksek ve en düşük verim arasında $2500 \mathrm{~kg} / \mathrm{da}$ 'lık fark belirlenmiştir. Bununla birlikte, Valentina hariç, çeşitlerin polar şeker oranı benzer bulunmuştur. Dolayısıyla çeşitlerin farklılığını belirleyen özelliğin kök-gövde verimi olduğu saptanmıştır. Bu nedenle çeşit seçimi yapılırken kök-gövde veriminin öncelikle göz önüne alınması gerektiği söylenebilir. İncelenen çeşitler arasında ise Esperanza, Maden ve Zanzibar'ın bölge şartlarında yüksek verim potansiyeline sahip olduğu sonucuna varılmıştır. 


\section{Kaynaklar}

Ada R., Akınerdem F., Öztürk Ö., 2012. Şeker Pancarı Çeşitlerinin Bazı Tarımsal ve Kalite Özelliklerinin Belirlenmesi. 1. Uluslararası Anadolu Şeker Pancarı Sempozyumu, 20-22 Eylül 2012, Kayseri, Bildiri Kitabı: 173-177

Anonim 2015a. http://tuikapp.tuik.gov.tr/bitkiselapp /bitkisel.zul (Erişim tarihi: 03.07.2015)

Anonim 2015b. http://www.tarim.gov.tr/BUGEM/ TTSM/Sayfalar/Detay.aspx?Sayfald $=85$ (Erişim tarihi: 03.07.2015)

Düzgüneş O., Kesici T., Kavuncu O., Gürbüz F., 1987. Araştırma ve Deneme Metotları (İstatistik Metodları II). A.Ü. Ziraat Fakültesi Yayınları:1021. Ders Kitabı, $295 \mathrm{~s}$

Günel E., İlbaş A.İ., 1994. Van ekolojik şartlarında bazı şeker pancarı (Beta vulgaris) çeşitlerinin verim ve kalitesi üzerine bir araştırma. Yüzüncü Yıl Üniversitesi Ziraat Fakültesi Dergisi, 4 : 95-112
Karadoğan T., Kurtçebe Ş., 2005. Göller Yöresine Uygun Şeker Pancarı Çeşitlerinin Belirlenmesi. Türkiye VI. Tarla Bitkileri Kongresi, 5-9 Eylül 2005, Antalya, Cilt I: 441446

Okut N. ve Yıldırım B., 2004. Van koşullarında şeker pancarı (Beta vulgaris var. saccharifera L.)'nda çeşit ve ekim zamanının verim, verim unsurları ve kalite üzerine etkisi. Yüzüncü Yıl Üniversitesi, Ziraat Fakültesi, Tarım Bilimleri Dergisi (J. Agric. Sci.), 14(2): 149-158

Tunçtürk M., 2005. Bazı Şeker Pancarı Çeşitlerinin Van-Gevaş Koşullarında Verim Performanslarının Karşılaştırılması. Türkiye VI. Kongresi, Cilt 1, sayfa 437-440, 5-7 Eylül 2005, Antalya 